\title{
A smart cascaded H-bridge multilevel inverter with An optimized modulation techniques increasing the quality and reducing harmonics
}

Youssef Babkrani, Ahmed Naddami, Mohamed Hilal

Departement of Electrical Engineering, University of Hassan 1ST National Faculty of Science and Technical, Morocco

\begin{tabular}{l} 
Article Info \\
\hline Article history: \\
Received Mar 20, 2019 \\
Revised Jun 10, 2019 \\
Accepted Jul 8, 2019 \\
\hline Keywords: \\
Cascaded H bridge \\
Phase disposition \\
Phase opposition disposition \\
Smart Multi-level inverter \\
Total Harmonics Distortion
\end{tabular}

Article Info

Article history

Received Mar 20, 2019

Revised Jun 10, 2019

Accepted Jul 8, 2019

\begin{abstract}
The world community relied heavily on fossils energies but just after the big oil crisis the use of renewable energy has greatly increased and has become the main interest of many countries for its many advantages such as: minimal impact on the environment, renewable generators requiring less maintenance than traditional ones and it has also a great impact on economy. It is easy to get charmed by the advantages of using the renewable resources but we must also be aware of their disadvantages. One of the major disadvantages is that the renewable energy resources are intermittent and thus they have led scientists to develop new semiconductor power converters among which are the multilevel inverter. In this paper a new smart multi-level inverter is proposed so as to increase its levels according to the user's needs and also to avoid the impact of shades and the intermittence on photovoltaic panels. We also propose a modification on the multicarrier aiming to reduce the harmonics. This modification introduces a sinusoidal wave compared with trapezoidal multi-carrier to generate the pulses. In order to obtain the line voltages and the total harmonic distortions (THD) MATLAB/SIMULINK is used.
\end{abstract}

Copyright (c) 2019 Institute of Advanced Engineering and Science. All rights reserved.

\section{Corresponding Author:}

Babkrani Youssef,

Departement of Electrical Engineering,

University of Hassan 1ST,

Faculty of Science and Technical, Settat,

Email: y.babkrani@gmail.com

\section{INTRODUCTION}

The world around us has changed considerably over the past 20 years. As fossil fuels become more expensive and tougher to find and also because energy fuels related activities have led to significant environmental damages [1]. Thus it is a wiser decision for governments all around the world to reduce their dependency on such traditional types of energy and replace it with other sources of energy that can be safer, cheaper cleaner and renewable, solar energy is undeniably one of these sources, using solar radiation to produce the heat and electricity [2]. Solar energy demand has grown by $25 \%$ annually during the past 20 years [3]. However, its utilization has met different difficulties the major ones are power quality and the intermittent of renewable energy resources [4].

Power Quality has been a problem ever since electrical power was invented and in recent years, it has become the main interest of researchers who are still concerned about finding ways to reduce its negative influence on electrical devices. Harmonics are an important factor in power quality and also to maintain stable power supply performance [5], so the inverters with harmonics reduction is required multilevel inverters are gaining celebrity for Photovoltaic (PV) systems due to the reduced total harmonic distortions of the output signal and the low voltage stress of power switches. It produces almost a sinusoidal voltage at the output [6]. In addition, two-level inverters are exposed to thermal stresses created by converting the full 
voltage imposed by the continuous source, so the performance and lifetime of its components are actually affected. In this scenario, a new smart multilevel inverter is proposed with a modified command system aiming to reduce more harmonics on the output signal and also it will allow every solar panel in the system to operate independently so the total energy system will not be excessively affected by shades and intermittent. Cascaded H-bridge multilevel is found to be attractive for our smart inverter because it uses the same technology in series "full H-Bridges" to produce inverted AC from separate DC sources [7].

This paper presents a proposition of a smart cascaded h-bridge multi-levels inverter with the possibility of increasing the levels according to the need of the user. Multiple multi-carrier SPWM methods for cascaded h-bridge are analyzed and compared with the conventional SPWM technique. Those carriers are being implemented with different sinusoidal dispositions PD, POD and APOD and with different frequencies.

\section{MULTI-LEVEL INVERTER}

\subsection{Induction motors}

Big electric energies uses include advanced power electronics inverter to encounter the high demands. As a result, multilevel voltage inverter has been presented as an alternative in high power and medium voltage circumstances [8]. A multilevel converter not only attains high power assessments, but also it increases the performance of the whole structure in terms of harmonics [9].Many present schemes incorporate the use of induction motors as main source for traction in electric vehicles, those driver require advanced power electronic inverters, to attain their high power demands.

The multilevel voltage inverters structure allows them to grasp this high voltage requirement without the usage of transformers [10], especially high voltage vehicle drives where electromagnetic interference (EMI) and low total harmonic distortion (THD) of the output voltage are vital.

The general utility of the multilevel inverter is to create a desired voltage from multiple levels of dc voltages, for this reason, multilevel inverters can easily deliver the high power necessary to large electrical Vehicles, hybrid Vehicles or any motor inverter technology used mainly in areas of high energy consumption such as air conditioning. as [11]:

Cascade inverters are perfect for an induction motor this configuration gives many advantages such

a) It makes induction motor safer /handy for induction motor power system.

b) No electromagnetic interference.

c) Higher efficiency is attained compared to low voltage motors.

d) Low voltage switching devices are used.

e) No unbalance charge problem in drive mode or charge mode.

\subsection{Basic structure}

A cascaded multilevel inverter is a power electronic device made to create a desired AC voltage from several of DC voltages the structure is composed of several H-bridges converters in series connection as given in Figure 1 it got many advantages it can reach high voltage and high power without transformers and with a remarkable improvement of the spectral quality [12] . DC sources

The voltage levels $\mathrm{L}$ of the cascaded $\mathrm{H}$ inverter is defined by $\mathrm{L}=2 \mathrm{~N}+1$, where $\mathrm{N}$ is the number of

The more $\mathrm{H}$ inverters are used the more levels of the output waveform are created and the shape becomes approximate to sinusoidal waveform.

The output voltage can be expressed as: and $+\mathrm{Vdc}$

Vout $=\mathrm{V} 1+\mathrm{V} 2+\mathrm{V} 3+\ldots . .+\mathrm{Vn}$. Each full bridge inverter can generate three levels $-\mathrm{Vdc}, 0$ 


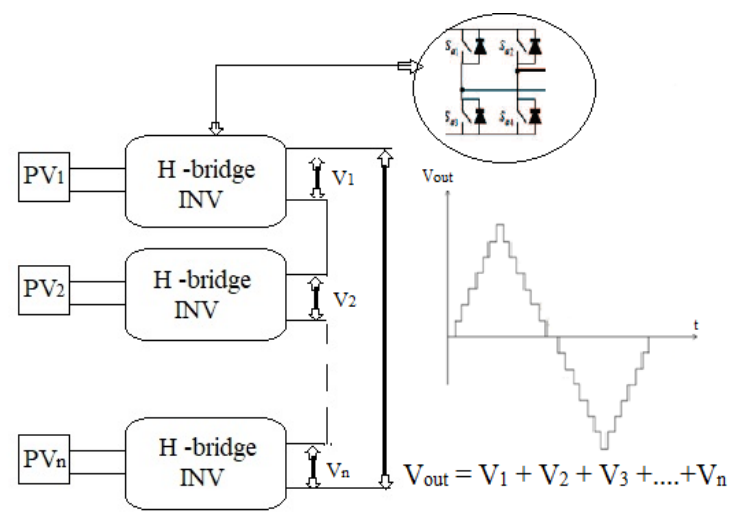

Figure 1. Structure of a Cascaded H Bridge

\subsection{Carrier-based modulation schemes}

Most carrier-based PWM schemes for cascaded H-bridge multi-level inverters descend from the carrier disposition scheme [13] For an L level cascaded inverter, L-1 triangular carriers is used with the same frequency and amplitude so that they fully occupy the range [14]. A single reference sinusoidal signal with low frequency is been continuously compared with each carrier to determine the switched device.

Three carrier disposition PWM strategies are well known and referenced [15]:

a) Phase disposition (PD), carriers are in the same phase Figure 2.

b) Phase opposition disposition (POD), carriers above zero are $180^{\circ}$ phase shifted with those below

c) Alternative phase opposition disposition (APOD), where the carriers are alternately $180{ }^{\circ}$ phase shifted

In this paper, different multi-carrier shapes (Triangular, Trapezoidal) are used and the performances are analyzed to prove the best techniques [16]

The results are obtained when using those techniques with different sinusoidal dispositions PD PWM, POD PWM and APOD PWM.

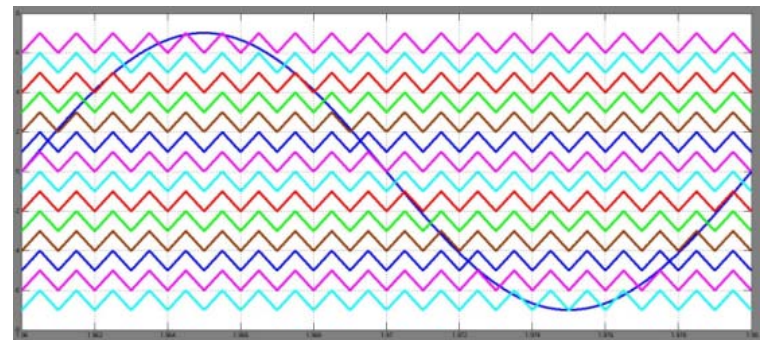

Figure 2(a). Triangular multi-carriers with Phase disposition (PD) arrangement

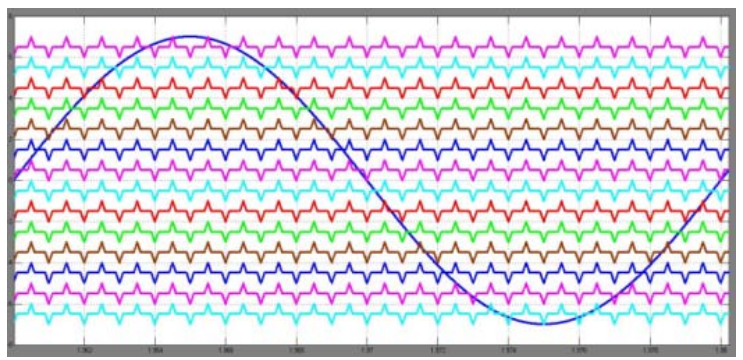

Figure 2(b). Trapezoidal multi-carriers with Phase disposition (PD) arrangement. 
The equation (1) for trapezoidal carrier can be inserted in DSP defined as:

Where $\mathrm{A}$ is the amplitude and $\mathrm{T}$ is the period of the carrier signal.

$$
U(t)=\left\{\begin{array}{c}
\frac{t}{t 1}\left(\frac{A}{2}\right) 0 \leq t<t 1 \\
A / 2 t 1 \leq t<t 2 \\
{\left[\frac{\mathrm{t}-\mathrm{t} 2}{\mathrm{t} 3-\mathrm{t} 2}\right]\left(\frac{\mathrm{A}}{2}\right)+\mathrm{A} / 2 \mathrm{t} 2 \leq \mathrm{t}<\mathrm{t} 3} \\
{\left[\frac{\mathrm{t} 4-\mathrm{t}}{\mathrm{t} 4-\mathrm{t} 3}\right]\left(\frac{\mathrm{A}}{2}\right)+\mathrm{A} / 2 \mathrm{t} 3 \leq \mathrm{t}<\mathrm{t} 4} \\
\mathrm{~A} / 2 \mathrm{t} 4 \leq \mathrm{t}<\mathrm{t} 5 \\
{\left[\frac{\mathrm{t}-\mathrm{t} 6}{\mathrm{t} 5-\mathrm{t} 6}\right]\left(\frac{\mathrm{A}}{2}\right) \mathrm{t} 5 \leq \mathrm{t}<\mathrm{t} 6}
\end{array}\right.
$$

\section{THE TOTAL HARMONIC ANALYZE}

The total harmonic distortions (THD) are evaluated through all the modulation techniques and for various frequencies.

To acquire the spectrum of the output voltage (THD) Fast Fourier Transform (FFT) is applied [17]. The THD is calculated using the following equation (2) [18]:

$T H D=\frac{\sqrt{\sum_{n=2}^{\infty} v_{n}^{2}}}{v_{1}}$

Where:

$\mathrm{n}$ is the harmonic order.

$\mathrm{V}_{\mathrm{n}}$ is the root mean square (RMS) value of the $\mathrm{n}^{\text {th }}$ harmonic component .

$\mathrm{v}_{1}$ is the (RMS) value of the fundamental component.

The output voltage wave-forms Figure 3 and the total harmonic distortions Figure 4a,b are acquired for both types of multi-carriers.

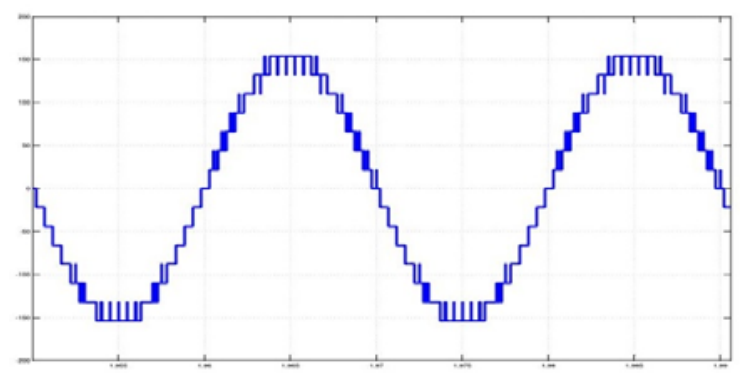

Figure 3. The output voltage wave-forms

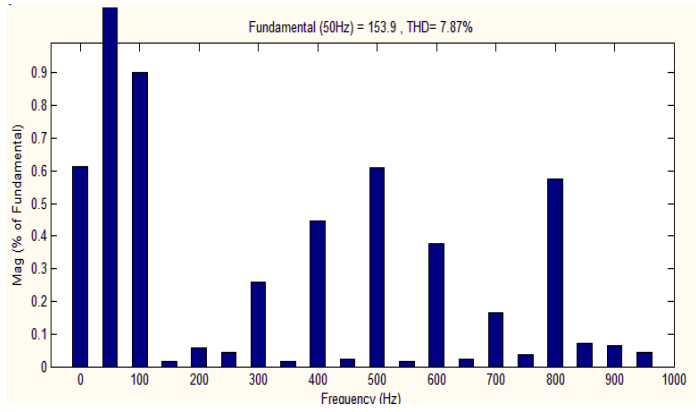

Figure 4 (a). FFT Analysis of the Output using Triangular carriers

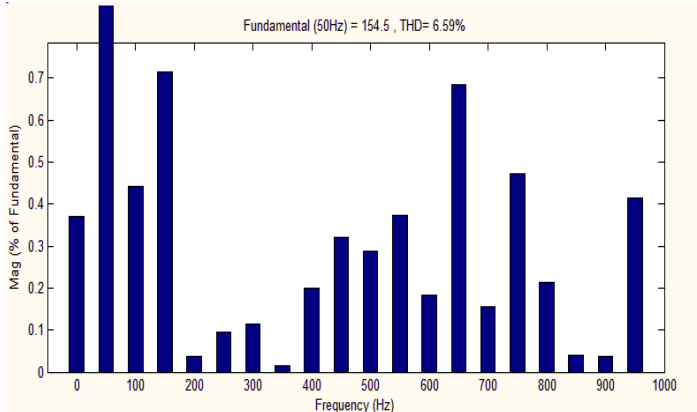

Figure 4 (b). FFT Analysis of the Output using modified Trapezoidal carriers

A smart cascaded H-bridge multilevel inverter with An optimized modulation tech ... (Babkrani Youssef) 
The Table 1 resumes all harmonics distortion results for both multi-carrier techniques with different frequencies.

Table 1. The harmonic distortion analyses.

\begin{tabular}{|c|c|c|c|c|}
\hline $\begin{array}{r}\text { Techniques } \\
1 \\
\end{array}$ & Dispositions & $\begin{array}{c}\text { Phase } \\
\text { Dispositions }\end{array}$ & $\begin{array}{c}\text { Phase } \\
\text { opposite } \\
\text { disposition }\end{array}$ & $\begin{array}{c}\text { Alternative } \\
\text { phase opposite } \\
\text { disposition }\end{array}$ \\
\hline \multirow{2}{*}{ Triangular } & $1 \mathrm{KHz}$ & $8.27 \%$ & $8.28 \%$ & $9.45 \%$ \\
\hline & $2 \mathrm{KHZ}$ & $7.87 \%$ & $8.68 \%$ & $8.14 \%$ \\
\hline \multirow{2}{*}{ Trapezoid } & $1 \mathrm{KHz}$ & $6.71 \%$ & $7.39 \%$ & $7.20 \%$ \\
\hline & $2 \mathrm{KHZ}$ & $6.59 \%$ & $7.06 \%$ & $6.74 \%$ \\
\hline
\end{tabular}

It confirms that the best performance for triangular carriers is when phase disposition with $2 \mathrm{KHz}$ frequency is used and after using the trapezoidal carriers better results are obtained with a gain of $1.28 \%$.

So it is clear that this new modification is best suited for Cascaded Multi-Level with the improvement of the output signal quality which makes it more suitable for both standalone and grid connected systems.

\section{SMART MULTI-LEVEL INVERTER}

\subsection{Shades}

In most solar photovoltaic (PV) systems it contains about 6 to 30 panel [19], to encounter the voltage necessities of the system's inverter, solar arrays are usually alienated into strings of solar panels but those strings are usually consisted form more than one single panel [20].

If shade is on even one of the panels in the string, the output of the entire string will be reduced to nearly zero [21] for as long as the shadow stands there. In some cases, a shadow does not essentially need to descent on a whole panel, even just one cell could crush the output of the panel and turn off the entire string and becomes a receiver that will heat up and lead to a loss of production or even worse Figure 5 [22].

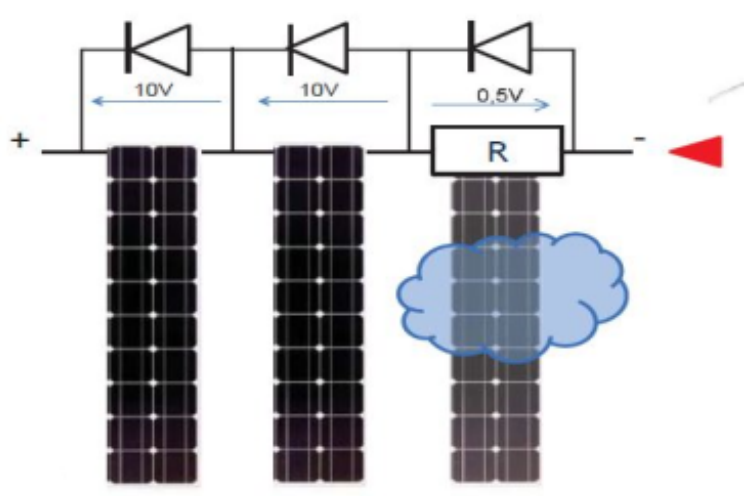

Figure 5. Effect of shades on photovoltaic panels

The smart multilevel inverter Figure 6 proposed in this paper will have the possibility of increasing levels of the output according to the need of the user mainly according to the number of continuous DC sources available and also according to the power desired. In this way it will allow every solar panel in the system to operate independently and the total energy system will not be excessively affected by any shaded panels and at the same time it can be replaced by a storage battery.

The user will have multiple of h-bridge cards Figure 7, those cards can be inserted in another card with slots to increase the levels; the number of inserted card must be the same as the continuous sources disposed.

Int J Pow Elec \& Dri Syst Vol. 10, No. 4, Dec 2019 : 1852 - 1862 


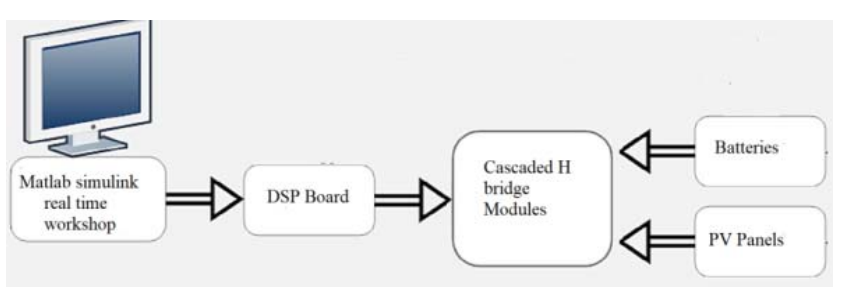

Figure 6. Smart cascaded system

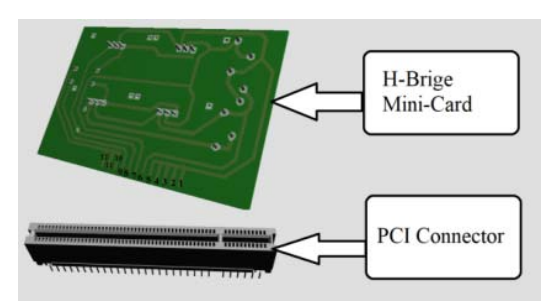

Figure 7. H-bridge cards

\subsection{H-bridge with driver}

An output pulse $(+5 \mathrm{v})$ of a microcontroller is generally sufficient to drive a MOSFET dedicated to small signal. However, two problems arise when working with more powerful MOSFETs:

- The control signal of the $3.3 \mathrm{~V}$ or $5 \mathrm{~V}$ microcontrollers is not often enough. It is necessary to apply at least $8-12 \mathrm{~V}$ to completely ignite the MOSFET which can cause their destruction [23].

- Without drivers MOSFET switching can cause a feedback to the control circuit, while the drivers are designed to handle this problem [24].

Since we will convert voltages higher than $+30 \mathrm{~V}$ we will need drivers (IR2304) in our circuits, it will maximize the switching speed by injecting current so that the MOSFET spends the least possible time in transition time, and so we will have a minimum waste of energy and heat on components [25].

For simulation purposes, Proteus ISIS was used Figure 7 to simulate the H-bridge system alongside the MOSFET drivers, with microcontroller programming and all switching devices.

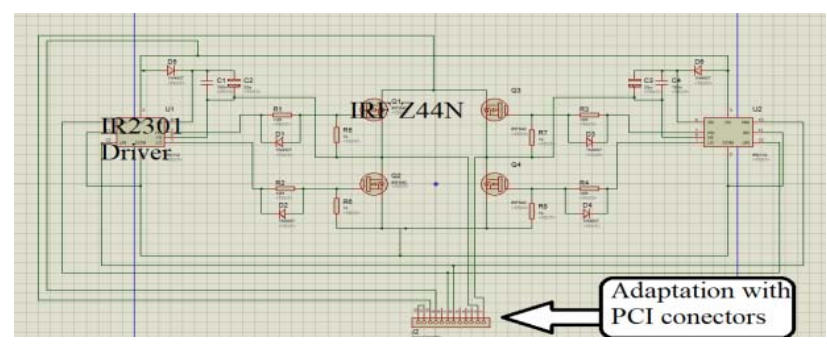

Figure 8. H Bridge with MOSFET Drivers

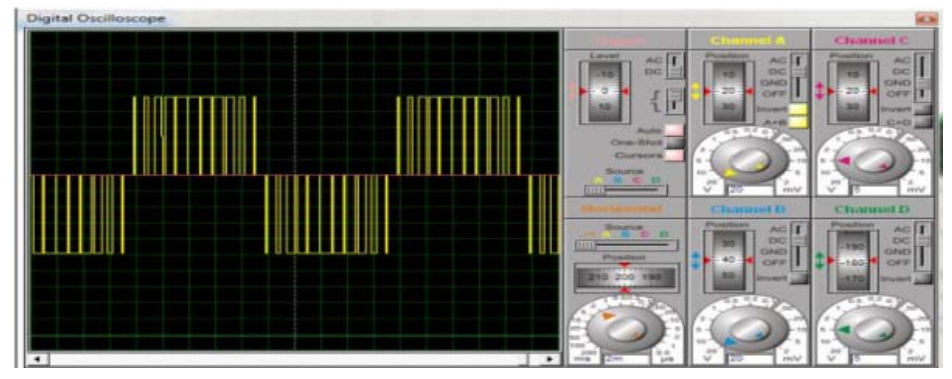

Figure 9. The output voltage of the H-bridge inverter

\section{EXPERIMENTAL RESULTS}

As for Experimental results, the output voltage designed for the system is 230 AC supply Figure 9c. In order to reach it the input supply used is $34 \mathrm{~V}$ for each different inverter stages, for all switching devices MOSFETs IRF 44ZN are utilized in order to obtain high efficiency over an extensive load range. The DSP controller or arduino-mega is used to generate the switching pulses for switches based on POD, APOD and PD arrangements for PWM. The carrier signals above and below zero are levels shifted to realize PD, POD

A smart cascaded H-bridge multilevel inverter with An optimized modulation tech ... (Babkrani Youssef) 
and APOD signals. And to generate the pulses required for the MOSFET switches these signals are been compared continuously with the reference sinusoidal signal.

When the inverter starts working, the microcontroller generates a $5 \mathrm{v}$ signal to detect the number of cards inserted. Then, a code of 7 digits received will be equivalent to the number and the location of each card. For example, the reception of 0000001 code means that only one card is inserted and the location of the card is in the first slot.

After the testing, the program to produce the switching pulses will be generated corresponding to the code listed and will keep functioning until the inverter's shutdown. As for relays Figure 9 it will let the current flow if there is no h-bridge card inserted. For every h-bridge card the following equipment's Table 2 is needed:

Table 2. H-bridge Materiels.

\begin{tabular}{cc}
\hline Quantities & Materials \\
\hline 4 & 10R Resistors \\
4 & 1k Resistors \\
2 & 33uF/16v capacities \\
2 & IR2304 Drivers or IR2301 \\
4 & IRF Z44N Transistors \\
6 & 1N4007 Diodes \\
\hline
\end{tabular}

The experimental prototype is illustrated on Figure 10(a) along with the PCB layout for every hbridge card:

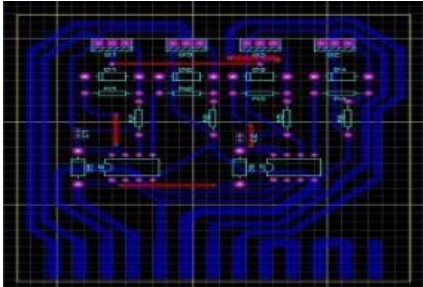

PCB design on ARES

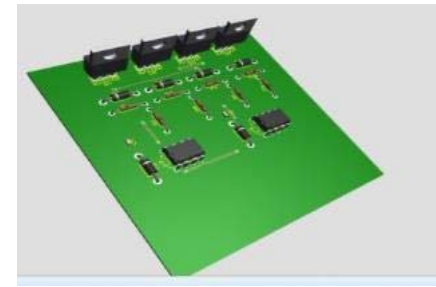

$3 D$ view of the h-bridge card

Figure 10(a). PCB layout for h-bridge cards
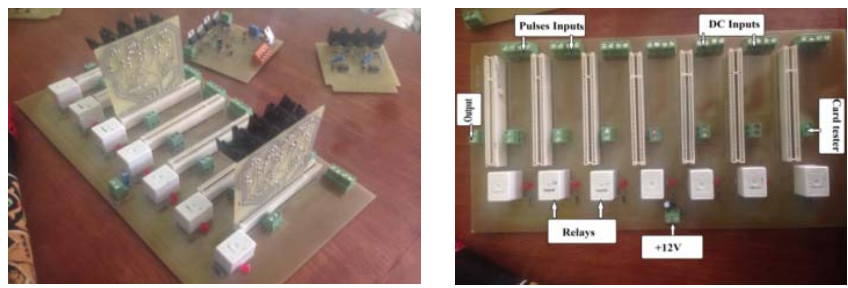

Figure 10(b). Suggested smart multi-level inverter

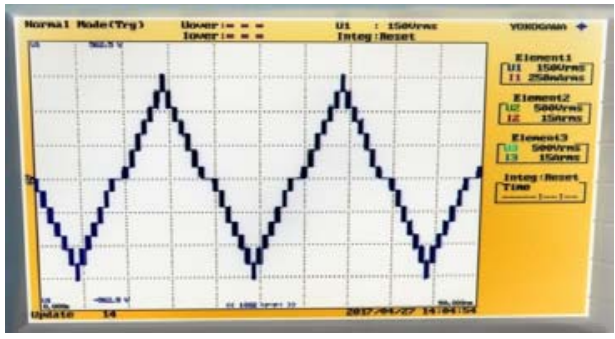

Figure 10(c). Voltage output of fifteen multi-level inverter 
According to this system, Phase disposition multi-carrier modulation techniques are used and the output and the performances are analyzed. Figure 10(b) shows the suggested smart multi-level inverter system made up to analyze the performances of a cascaded fifteen levels inverter.

This system is devised into four major parts:

Part 1: Pulses Inputs, where Multi-carrier PWM techniques are inserted (The Command part)

Part 2: DC inputs where, Photo-voltaic DC sources or batteries are used (DC inputs)

Part 3: Relays will let the current flow if there is no h-bridge card inserted.

Part 4: The output voltage after DC conversion (AC output).

For experimental application. The PWM scheme was executed in MOSFETs IRFZ44N using an Arduino Mega 2560 and for better comparison, the same configurations are used in the simulation and experimentation. The output voltage waveform is shown in Figure 10(c). It can be seen that the experimental result match with simulation. A comparison between the cascaded topology of a seven and a fifteen multilevel inverter is done and the results are shown in Table 2, Figures 11(a-j) which clearly shows the percentage reduction in the total harmonic distortion by increasing the number of levels "N".

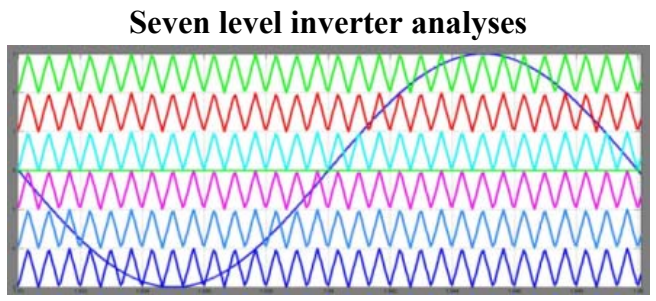

Figure 11(a). Multi-carriers PD arrangement for a seven level inverter

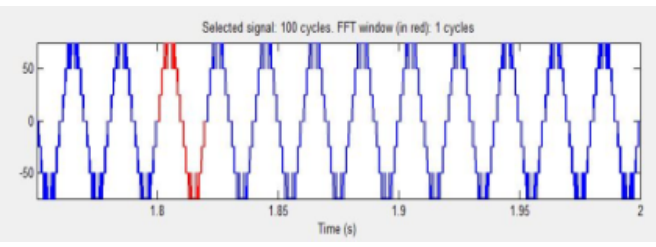

Figure 11(b). Seven multi-level inverter output signal

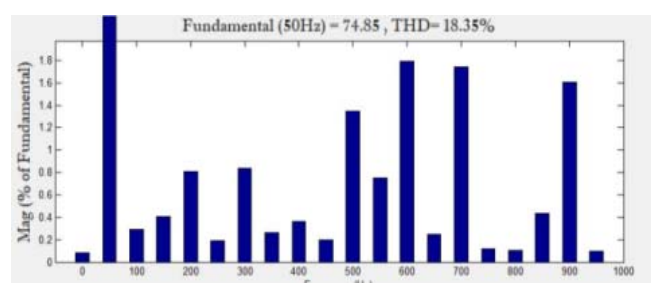

Figure 11(c). Seven multi-level inverter THD analysis of POD

\section{Fifteen level inverter analyses}

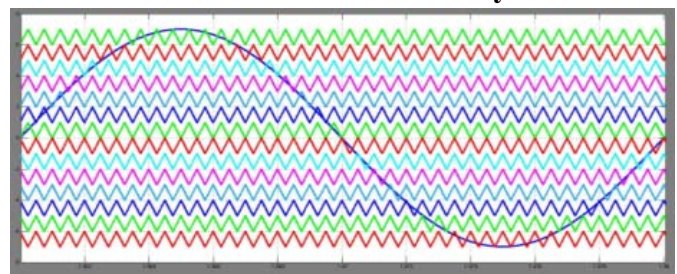

Figure 11(f). Multi-carriers POD arrangement for a fifteen level inverter

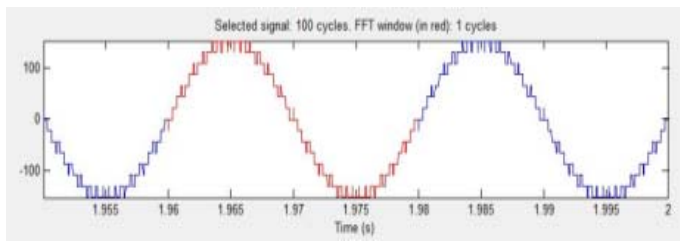

Figure 11(g). Fifteen multi-level inverter output signal

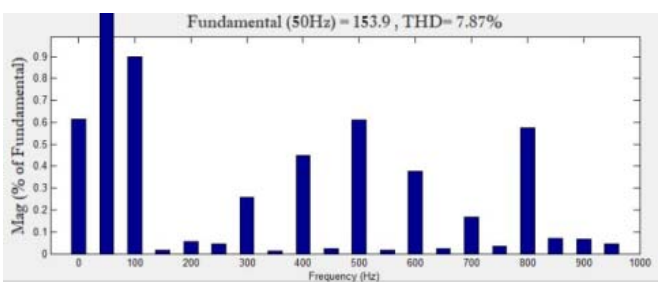

Figure 11(h). Fifteen multi-level inverter THD analysis of PD 


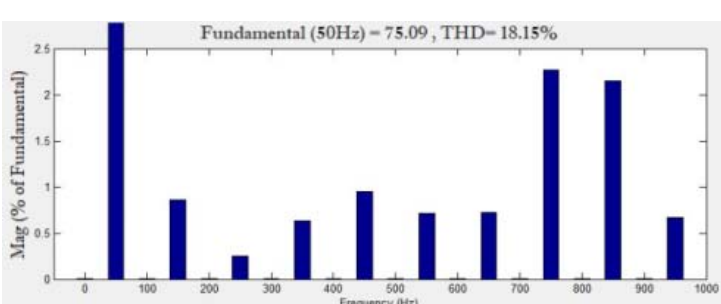

Figure 11(d). Seven multi-level inverter THD analysis of APOD

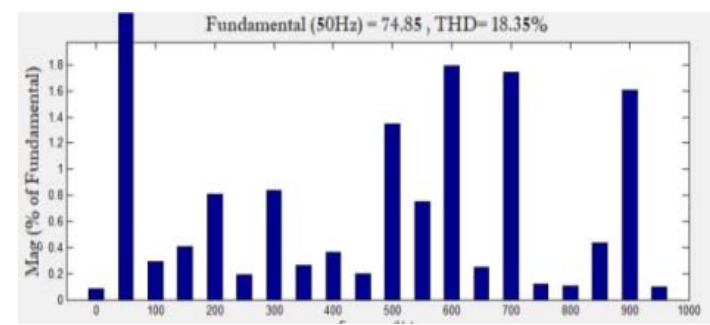

Figure11(e). Seven multi-level inverter THD analysis of APOD

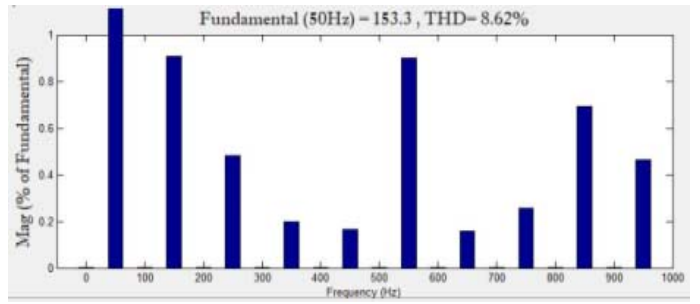

Figure 11(i). Fifteen multi-level inverter THD analysis of POD

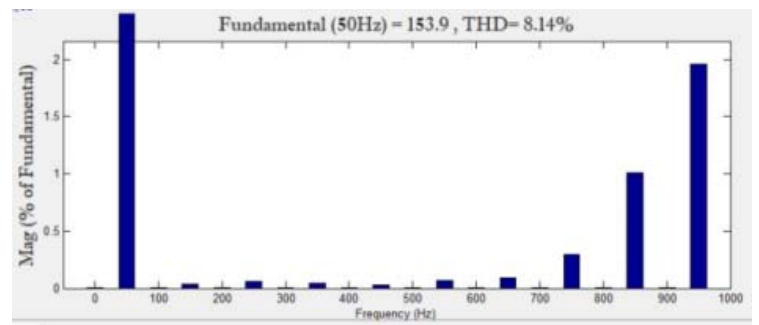

Figure 11(j). Fifteen multi-level inverter THD analysis of APOD

\section{RESULTS INTERPRETATION}

About DC/AC conversion, the harmonic analysis of output voltages is shown in Figure 12, the fifteen levels inverter generates less Total Harmonic Distortion (THD) and higher output quality for every multi-carriers technical disposition (PD, POD, APOD). Based on obtained results increasing the number of "N" level increases greatly the quality of the output signal by reducing the total harmonic distortion so it clear that increasing levels makes it more suitable for applications where electromagnetic interference (EMI) and low total harmonic distortion (THD) of the output voltage are vital.

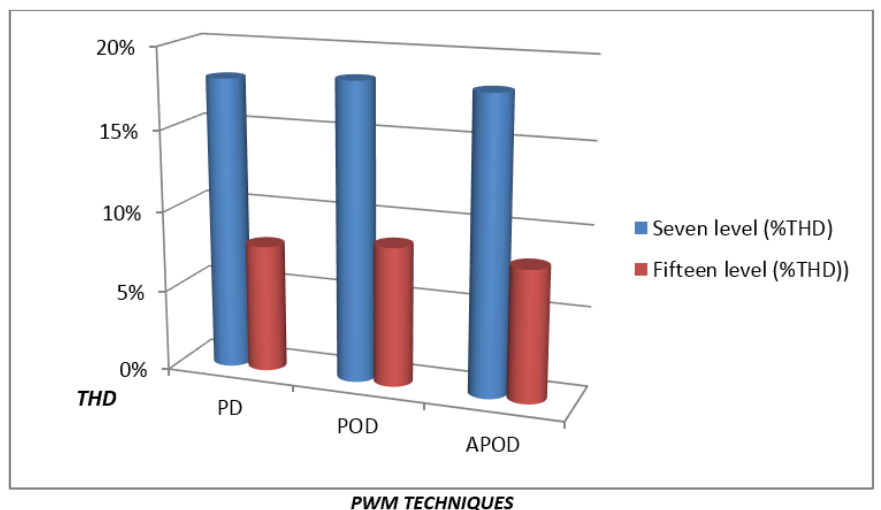

Figure12. THD analysis for the line voltages

\section{CONCLUSION}

The SPWM control scheme for the fifteen level cascaded $\mathrm{H}$ bridge inverter has been presented in this paper The PD PWM method has given the better results for all types of carriers, The results illustrate that after modifying the carriers better results can be obtained. 
The smart multilevel inverter suggested will allow every solar panel in the system to operate independently and the total energy system will not be extremely affected by shades or some intermittence.

A comparative study of a seven and fifteen multi- level inverter is done to illustrate the great improvement of the quality signal due to the $\mathrm{N}$ level of the multi-inverter.

It is clear that this new scheme is best suited for Cascaded Multi-Level with the improvement of the output signal quality which makes it more suitable for both standalone and grid connected systems.

\section{REFERENCES}

[1] B Xiao, L Hang, J Mei, \& C Riley., "Modular Cascaded H-Bridge Multilevel PV Inverter With Distributed MPPT for Grid-Connected Applications IEEE Transactions on Industry Applications," vol. 51, no. 2, pp. 1722-1731, Mar-Apr 2015.

[2] L Wang, D Zhang, Y Wang, \& B Wu., "Power and Voltage Balance Control of a Novel Three-Phase Solid-State Transformer Using Multilevel Cascaded H-Bridge Inverters for Microgrid Applications IEEE Transactions on Power Electronics," vol. 31, no. 4, pp. 3289-3301, Apr 2016.

[3] SS Letha, T Thakur, \& J Kumar., "Harmonic elimination of a photo-voltaic based cascaded H-bridge multilevel inverter using PSO (particle swarm optimization) for induction motor drive," vol. 107, no. 15, pp. 335-346, Jul 2016.

[4] A Abdulrazzaq and A H Ali, "Efficiency Performances of Two MPPT Algorithms for PV System With Different Solar Panels Irradiancess," International Journal of Power Electronics and Drive System (IJPEDS), vol. 9, no. 4, pp. 1755-1764, Dec 2018.

[5] O.Salama, A.Tabyaoui, \& M.Benchagra, "Control Methods on Three-phase Power Converters in Photovoltaic Systems," International Journal of Power Electronics and Drive System (IJPEDS), vol. 9, no. 4, pp. 1851-1865, Dec 2018.

[6] M Dabbaghjamanesh and A Moeini, "High Performance Control of Grid Connected Cascaded H-Bridge Active Rectifier Based on Type II-Fuzzy Logic Controller with Low Frequency Modulation Technique," International Journal of Electrical and Computer Engineering (IJECE); vol. 6, no. 2, pp. 484-494, Apr 2016.

[7] J Sastry, P Bakas, H Kim, L Wang, \& A Marinopoulos., "Evaluation of cascaded H-bridge inverter for utilityscale photovoltaic systems," Renewable Energy,vol. 69, pp. 208-218, Sep 2014.

[8] Syed Munvar Ali, V. Vijaya kumar Reddy, \& M. Surya Kalavathi., "Coupled random PWM technique for dual inverter fed induction motor drive," International Journal of Power Electronics and Drive System (IJPEDS), vol. 10, no. 1, Mar 2019.

[9] VK Gupta and R Mahanty, "Optimized switching scheme of cascaded H-bridge multilevel inverter using PSO," International Journal of Electrical Power \& Energy Systems, vol. 64, pp. 699-707, Jan 2015.

[10] Nayeemuddin, T. Bramhananda Reddy, \& M. Vijaya Kumar., "Level Shifted Discontinuous PWM Algorithms to Minimize Common Mode Voltage for Cascaded Multilevel Inverter Fed Induction Motor Drive," International Journal of Power Electronics and Drive System (IJPEDS), vol 9, no. 2, Jun 2018.

[11] N.Prabaharan and K.Palanisamy, "Analysis and integration of multilevel inverter configuration with boost converters in a photovoltaic system," Energy Conversion and Management, vol. 128, no. 15, pp. 327-342, Nov 2016.

[12] M. Porselvi, K. Deepa, \& R. Muthu., "FPGA Based Selective Harmonic Elimination Technique for Multilevel Inverter”, International Journal of Power Electronics and Drive System (IJPEDS), vol 9, no. 1, Mar 2018.

[13] T P Kakosimos, K Pavlou, A Kladas, \& S Manias., "A single-phase nine-level inverter for renewable energy systems employing model predictive control," Energy Conversion and Management, vol 89(1), pp. 427-437, Jan 2015.

[14] M Coppola, F Di Napoli, \& P Guerriero, "An FPGA-Based Advanced Control Strategy of a Grid-Tied PV CHB Inverter", IEEE Transactions on Power Electronics, vol. 31, no. 1, pp. 806-816, Jan 2016.

[15] S Vijaya Madhavi and G. Tulasi Ram Das, "Comparative Study of Controllers for an Isolated Full Bridge Boost Converter Topology in Fuel Cell Applications," International Journal of Power Electronics and Drive System (IJPEDS), vol 9, no. 4, Dec 2018.

[16] Y Babkrani, A Naddami, S Hayani, \& M Hilal., "Selective-harmonic elimination with an optimized Multicarrier Modulation Techniques for Cascaded H-Bridge Multilevel Inverter," Journal of Applied Mathematics and Computation, vol. 3, no. 1, pp. 574-582, 2019.

[17] G.Vidhya Krishnan, M.Valan Rajkumar, \& C.Hemalatha, "Modeling and Simulation of 13-level Cascaded Hybrid Multilevel Inverter with less number of Switches," International Journal of Innovative Studies in Sciences and Engineering Technology ISSN 2455-4863 (IJISSET), vol. 2, no. 11, Nov 2016.

[18] Yusnida Ahmad Tarmizi, Auzani Jidin, Kasrul Abdul Karim, \& T. Sutikno., "A simple constant switching frequency of direct torque control of brushless DC motor," International Journal of Power Electronics and Drive System (IJPEDS), vol 10, no. 1, Mar 2019.

[19] Selvamuthukumaran, "A Garg Hybrid Multicarrier Modulation to Reduce Leakage Current in a Transformerless Cascaded Multilevel Inverter for Photovoltaic Systems," IEEE Transactions on Power Electronics, vol. 30, no. 4, Apr 2015.

[20] Kittaya Somsai., "Controller Design of UPQC for Enhancing Power Quality in Distribution System," International Journal of Power Electronics and Drive System (IJPEDS), vol 9, no. 4, Dec 2018. 
[21] Norazlan Hashim, Zainal Salam, Dalina Johari, \& Nik Fasdi Nik Ismail., "DC-DC Boost Converter Design for Fast and Accurate MPPT Algorithms in Stand-Alone Photovoltaic System," International Journal of Power Electronics and Drive System (IJPEDS), vol 9, no. 3, Sep 2018.

[22] RR Karasani and VB Borghate, "A Three-Phase Hybrid Cascaded Modular Multilevel Inverter for Renewable Energy Environment," IEEE Transactions on Power Electronics, vol. 32, no. 2, Feb 2017.

[23] Mahrous Ahmed, Essam Hendawi, \& Mohamed K. Metwaly., "Single Phase Asymmetrical Cascaded MLI with Extreme Output Voltage Levels to Switch Ratio," International Journal of Power Electronics and Drive System (IJPEDS), vol 9, no. 2, Jun 2018.

[24] Fethi Chouaf and Salah Saad, "A New Structure of the Nine Level Inverter Used as Active Power Filter with a Reduced Number of Swiches," International Journal of Power Electronics and Drive System (IJPEDS), vol. 9, no. 1, Mar 2018.

[25] Y Yu, G Konstantinou, \& B Hredzak, "Operation of Cascaded H-Bridge Multilevel Converters for Large-Scale Photovoltaic Power Plants Under Bridge Failures," IEEE Transactions on Industrial Electronics, vol. 62, no. 11, pp. 7228-7236, Nov 2015.

\section{BIOGRAPHIES OF AUTHORS}

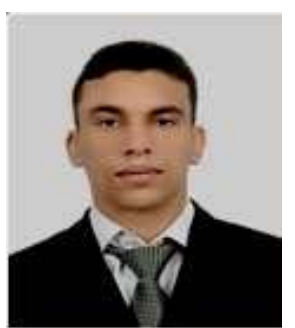

Youssef Babkrani was born in Sefrou, Morocco, in 1987. He received the Master degrees, in Electrical Engineering from the Faculty of Sciences and Techniques, Mohammedia. He pursues his doctoral program at at the Faculty of Sciences and Techniques, Hassan 1st university. His research interests are power electronics, automatic control and renewable energy.

(e-mail:y.babkrani@gmail.com)

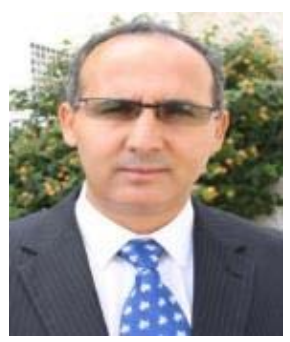

Ahmed Naddami received his engineering degree in electro-mechanics from the Higher School of Technical Education, Rabat-Morocco in 1994. In 2001, he received his Phd in electromechanics and instrumentation from Hassan 2nd University, Casablanca-Morocco. Then, he moved to Bordeaux University and worked as researcher. In 2004, he was hired as professor assistant at Hassan 1st University, Settat-Morocco and is currently the head of the electrical engineering department and the head of the Applied Mathematics and Information Technology laboratory in Hassan 1st University, Settat-Morocco. He writes and presents widely on issues of online and electrical engineering and renewable energy.

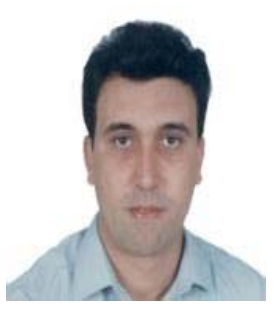

Mohamed HILAL was born in Assoul/Tinghir, Morocco. He obtained his Ph.D. in Electrical Engineering at Mohammadia School of Engineers in Rabat, Morocco, in 2014. Dr. HILAL Mohamed is currently professor at the higher institute of health sciences and director of the center for rapid prototyping of research and innovation complex of hassan first University in Settat, Morocco 